\title{
Analysis of Speaker Introduction Formality by Gender at the American College of Gastroenterology 2020 Annual Scientific Meeting
}

\author{
Lauren D. Feld ${ }^{1}(1) \cdot$ Erin R. Cleveland ${ }^{1} \cdot$ Loren G. Rabinowitz ${ }^{2} \cdot$ Vijaya L. Rao $^{3} \cdot$ Daniel Bushyhead $^{4} \cdot$ Thomas Couri $^{3}$. \\ Rachel B. Issaka ${ }^{1,5,6}$
}

Received: 10 February 2021 / Accepted: 21 May 2021 / Published online: 18 July 2021

(c) The Author(s), under exclusive licence to Springer Science+Business Media, LLC, part of Springer Nature 2021

\begin{abstract}
Background Gender-based differences in the use of professional titles during speaker introductions have been described in other medical specialties.

Aims Our primary aim was to assess gender-based differences in the formality of speaker introductions at the American College of Gastroenterology 2020 Virtual Annual Scientific Meeting. Our secondary aim was to assess gender-based differences in the formality of speaker self-introductions.

Methods Reviewed presentations from the American College of Gastroenterology Annual Meeting for gender-based differences in professional title use during speaker introductions and self-introductions.

Results Speakers included 29 women (37.2\%) and 49 men (62.8\%). We found no significant gender differences in the use of professional titles by introducers $(t(67)=-0.775, p=0.441)$ or in self-introductions $(36.4 \%$ of women vs. $41.9 \%$ of men, $t(63)=0.422, p=0.674)$.

Conclusion The lack of gender differences in professional title use may represent a novel advantage of virtual meeting formats or suggest increased attention to gender bias in introductions.
\end{abstract}

Keywords Gender equity · Professionalism · Bias · Microaggressions

An editorial commenting on this article is available at https://doi. org/10.1007/s10620-021-07139-3.

Lauren D. Feld

lfeld@uw.edu; ldfeld@gmail.com

Erin R. Cleveland

ecleve@uw.edu

Loren G. Rabinowitz

Lorengr@gmail.com

Vijaya L. Rao

Vijayarao@medicine.bsd.uchicago.edu

Daniel Bushyhead

dwbushyhead@houstonmethodist.org

Thomas Couri

couring@gmail.com

Rachel B. Issaka

rissaka@fredhutch.org

1 Division of Gastroenterology, University of Washington

School of Medicine, 1959 NE Pacific Street, Box 356424,

Seattle, WA 98195, USA
2 Division of Gastroenterology, Department of Medicine, Beth Israel Deaconess Medical Center, Harvard Medical School, Boston, MA 02215, USA

3 Section of Gastroenterology, Hepatology \& Nutrition, University of Chicago, 5841 South Maryland Avenue, Chicago, IL 60637, USA

4 Lynda K and David M Underwood Center for Digestive Disorders, Division of Gastroenterology, Houston Methodist Hospital, 4191 Bellaire Blvd, Houston, TX 77025, USA

5 Clinical Research Division, Fred Hutchinson Cancer Research Center, 1100 Fairview Ave N, Seattle, WA 98109, USA

6 Hutchinson Institute for Cancer Outcomes Research, Fred Hutchinson Cancer Research Center, 1100 Fairview Ave N, Seattle, WA 98109, USA 


\section{Introduction}

Gender bias in medicine contributes to persistent disparities in academic advancement for women [1, 2]. In gastroenterology, women remain underrepresented, accounting for approximately $16 \%$ of practicing gastroenterologists in the USA [3]. Women gastroenterologists report gender-based bias [4-7], with documented gender disparities in compensation, invited authorships, and leadership positions [8-10]. Studies in internal medicine and oncology have noted gender-based differences in the use of professional titles during speaker introductions $[11,12]$. These studies found that women physicians were less likely to be introduced by their professional titles, and that this difference was driven primarily by men introducing women physicians more informally than their colleagues who are men [11, 12]. This phenomenon has not yet been studied in gastroenterology. Our primary aim was to assess gender-based differences in the formality of speaker introductions at the American College of Gastroenterology (ACG) 2020 Virtual Annual Scientific Meeting. Our secondary aim was to assess gender-based differences in the formality of speaker self-introductions.

\section{Methods}

We conducted a retrospective, observational cohort study of video-archived speaker introductions from the 2020 ACG Annual Meeting. Following a data extraction training session, a team of mixed-gender coders collected data on introducer gender, degree, and academic rank, speaker gender, degree, and academic rank, event type, subject matter, and introduction formality. Gender was assessed using pronouns provided in the introductions and/or in professional websites and biographies, when available. Introductions were classified by four levels of formality: Dr. Last Name, Dr. First and Last Name, First and Last Name, and First Name only. These were later dichotomized into formal (Dr. Last Name or Dr. Full Name) or informal (First and Last Name or First Name only). Data analysis was performed with IBM SPSS Statistics Version 26 software. We reported demographics as proportions and used student's t-test to assess group differences.

\section{Results}

The ACG 2020 Meeting video archives included 26 sessions with 78 individual presentations. These archives included all speaker presentations during the conference, apart from those sponsored by pharmaceutical companies. Speakers included 29 women (37.2\%) and 49 men (62.8\%), with all
Formality of introductions by others

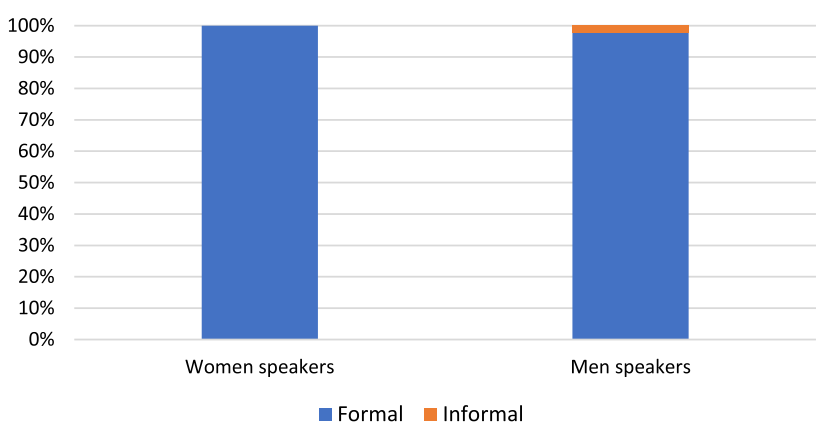

Fig. 1 Formality of introductions by other speakers for man and woman speakers

\section{Formality of self-introductions}

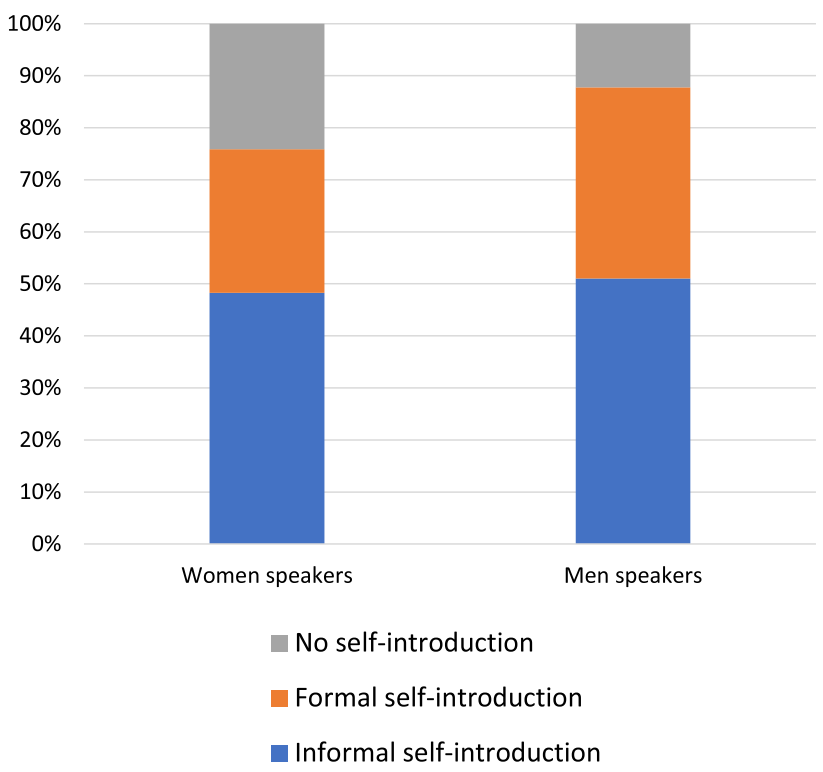

Fig. 2 Formality of self-introductions by man and woman speakers

speakers holding either an MD/DO and/or a PhD degree. The majority $(88.5 \%)$ of the speakers were introduced by another physician. Approximately one-third (30.4\%) of the speakers were introduced by women and the remainder (69.6\%) were introduced by men. In all but one instance, introducers used a formal introduction to refer to the speaker (Fig. 1).

Sixty-five of $78(83.3 \%)$ speakers introduced themselves at the beginning of their talk.

Of these, 26 provided a formal self-introduction (40.0\%) and 39 (50.0\%) provided an informal introduction (Fig. 2). An additional 13 speakers did not introduce themselves before beginning their talk. Among the 22 women speakers who self-introduced, 8 (36.4\%) introduced themselves formally and $14(63.6 \%)$ used an informal introduction. Of the 
43 men speakers who self-introduced, 18 (41.9\%) introduced themselves formally and 25 (58.1\%) used an informal introduction. There was no statistically significant difference in the formality of self-introductions by gender $(t(63)=0.422$, $p=0.674)$.

\section{Discussion}

In a review of presentations from the inaugural ACG 2020 Virtual Annual Meeting, we found no gender differences in the formality of speaker introductions or speaker self-introductions. This is in contrast to previously published work documenting gender-based difference in the use of professional titles in the introductions of speakers at in-person internal medicine and oncology conferences [11, 12]. The first article to formally evaluate speaker introductions at professional meetings in medicine was a retrospective observational study of video-archived speaker introductions at Internal Medicine Grand Rounds at two locations of an academic medical center. The findings published in 2017 highlighted that women were less likely to be addressed by professional title than men, and that this difference was driven by men introducing women speakers informally. Follow-up studies examining introductions at the 2017 and 2018 American Society of Clinical Oncology (ASCO) Annual Meetings and the American Academy of Dermatology 2019 annual meeting replicated these findings $[12,13]$. These important studies demonstrated the persistence of gender-based disparities in professional introductions across multiple medical disciplines and professional settings.

Professional titles may influence the perceived authority and knowledge of the referenced individual, and thus, as previous work has indicated, differences in use of professional titles may either explicitly or implicitly reinforce gender bias [11]. Our findings may represent an advantage of an online meeting format, which lends itself well to a standardized script to provide introductions which may lead to more uniform use of professional titles. In fact, ACG provided a detailed script for each introduction during the meeting. These scripts were consistent with the use of professional designations and institutions for each faculty introduction. This has implications for other conferences, suggesting that a standardized script may be helpful to reduce gender-based disparities in introductions. Additionally, our findings may reflect increasing societal awareness of gender-based disparities since the time of the previously mentioned publications, as well as increased efforts by the gastroenterology societies to address gender bias within our field [14]. Indeed, three articles published within the last year did not find gender-based differences in use of professional titles at the Society of Surgical Oncology (SSO) annual meetings in
2018 and 2019, the American Society for Radiation Oncology (ASTRO) annual meetings from 2017 to 2019, and the American Urological Association (AUA) annual conferences from 2017 to 2019, though the majority of speakers were men, and the sample sizes were limited [15-17].

To our knowledge, this is the first article to evaluate gender-based differences in introductions within gastroenterology, as well as the first study to assess self-introductions of speakers at a national medical conference. This study has several limitations. First, it is limited to a single conference, in a format that was novel at the time the conference took place. Indeed, the ACG annual meeting was one of the first major, national conferences to occur entirely virtually due to the COVID-19 pandemic. As recorded speaker presentations are only available from one year of this conference, our sample size is limited and this prevents us from comparing our findings to prior years. Second, we assessed use of professional address in introductions, but not during follow-up discussions after presentations. Importantly, data on gender should ideally be self-reported by each speaker, and this was not uniformly available due to the retrospective nature of our study. Finally, we did not have access to data on either speaker or moderator race, ethnicity, or other intersecting identities which may also influence our outcome of interest. Despite these limitations, we believe these findings are valuable and can inform ongoing efforts to address gender bias within our specialty and beyond.

In conclusion, we found no gender-based difference in professional title introductions, which is different from prior observational studies in other medical specialties. In this particular context, the virtual meeting format and increased awareness of gender disparities may have both contributed to more equal use of professional titles for men and women speakers. The authors are hopeful that manifestations of gender bias, such as disparities in use of professional titles, can be mitigated through identification and measures to reduce bias. Further research across other domains of gender bias and the intersectionality of gender, race, ethnicity, and other identifiers within gastroenterology is needed.

Author's contribution LDF: guarantor of the article; study design, data collection, data analysis, drafting and editing the manuscript. ERC: study design, data collection, drafting and editing the manuscript. LGR: study design, data collection, drafting and editing the manuscript. VLR: study design, drafting and editing the manuscript. DB: data collection, editing the manuscript. TC: data collection, editing the manuscript. RBI: study design, data analysis, drafting and editing the manuscript. All authors approved the final manuscript.

Funding Dr. Issaka receives funding from National Institutes of Health/National Cancer Institute award number K08 CA241296. The contents are solely the responsibility of the authors and do not necessarily represent the official views of the funders. 


\section{Declaration}

Conflict of interest The authors declare no conflicts of interest.

\section{References}

1. Jena AB, Khullar D, Ho O, Olenski AR, Blumenthal DM. Sex differences in academic rank in US Medical Schools in 2014. JAMA 2015;314:1149-1158.

2. Hamel MB, Ingelfinger JR, Phimister E, Solomon CG. Women in academic medicine-progress and challenges. $N$ Engl J Med 2006;355:310-312.

3. Gender breakdown of active physicians in 36 specialties. 2017. (Accessed April 9, 2021, at https://www.beckersasc.com/gastr oenterology-and-endoscopy/gender-breakdown-of-active-physi cians-in-36-specialties.html.)

4. Burke CA, Sastri SV, Jacobsen G, Arlow FL, Karlstadt RG, Raymond P. Gender disparity in the practice of gastroenterology: the first 5 years of a career. Am J Gastroenterol 2005;100:259-264.

5. Rabinowitz LG, Grinspan LT, Williams KE, et al. Gender dynamics in education and practice of gastroenterology. Gastrointest Endosc 2021;93:1047-1056.e5.

6. Singh A, Burke CA, Larive B, Sastri SV. Women in Gastroenterology Committee of American College of G. Do gender disparities persist in gastroenterology after 10 years of practice? Am J Gastroenterol 2008;103:1589-1595.

7. Arlow FL, Raymond PL, Karlstadt RG, Croitoru R, Rybicki BA, Sastri SV. Gastroenterology training and career choices: a prospective longitudinal study of the impact of gender and of managed care. Am J Gastroenterol 2002;97:459-469.

8. Bushyhead D, Strate LL. Sex-based disparities in annual compensation among academic gastroenterologists. Am J Gastroenterol 2021;116:219-220.
9. Bushyhead DW, Strate LL. 1166 female authorship of major gastroenterology society guidelines and technical reviews. Am J Gastroenterol 2019;114:S650-S652.

10. VanWagner LB, Issaka RB. The path to gastroenterology \& hepatology leadership: inadvertently perpetuating the glass ceiling and sticky floor. Gastroenterology 2021;160:2201-2202.

11. Files JA, Mayer AP, Ko MG et al. Speaker introductions at internal medicine grand rounds: forms of address reveal gender bias. $J$ Womens Health (Larchmt) 2017;26:413-419.

12. Duma N, Durani U, Woods CB et al. Evaluating unconscious bias: speaker introductions at an International Oncology Conference. $J$ Clin Oncol 2019;37:3538-3545.

13. Paradiso MM, Rismiller KP, Kaffenberger JA. Unconscious gender bias: a look at speaker introductions at the American Academy of Dermatology. J Am Acad Dermatol 2021;S0190-9622(21)00083-9.

14. Schmitt CM, Allen JI. View from the top: perspectives on women in gastroenterology from society leaders. Gastroenterol Clin North Am 2016;45:371-388.

15. Stewart CL, De Andrade JP, Duma $\mathrm{N}$ et al. Unconscious bias in speaker introductions at a surgical oncology meeting: hierarchy reigns over gender. Ann Surg Oncol 2020;27:3754-3761.

16. Huang $\mathrm{CC}$, Lapen $\mathrm{K}$, Shah $\mathrm{K}$ et al. Evaluating bias in speaker introductions at the American Society for Radiation Oncology Annual Meeting. Int J Radiat Oncol Biol Phys 2021;110:303-311.

17. Davuluri M, Barry E, Loeb S, Watts K. Gender bias in medicine: does it exist at AUA plenary sessions? Urology 2021;150:77-80.

Publisher's Note Springer Nature remains neutral with regard to jurisdictional claims in published maps and institutional affiliations. 